\title{
Relationship between Periodontal Disease Index and Low Birth Weight Babies in Pregnant Women with Periodontitis
}

\author{
Ira Komara, Soertini E. Lambri, Ina Hendiani \\ Department of Periodontology, Faculty of Dentistry, Universitas Padjadjaran
}

\begin{tabular}{|c|c|}
\hline Abstract & $\begin{array}{l}\text { Objective: To identify the relationship between periodontitis in pregnant } \\
\text { women through the periodontal disease index (PDI) and low birth weight } \\
\text { babies. }\end{array}$ \\
\hline & $\begin{array}{l}\text { Methods: A case-control study was conducted to determine the relationship } \\
\text { between periodontitis in pregnant women through the periodontal disease } \\
\text { index (PDI) and the low birth weight babies (LBW). The participants were } \\
\text { mothers with periodontitis and non-periodontitis mothers aged } 20-35 \text { years } \\
\text { who gave birth in the Department of Obstetrics and Gynecology-Dr. Hasan } \\
\text { Sadikin General Hospital, Bandung in the period of December to January } \\
2005 \text {. }\end{array}$ \\
\hline & $\begin{array}{l}\text { Results: Based on the chisquare test results a highly significant relationship } \\
\text { between periodontitis and low birth weight }(\mathrm{p}=0.002) \text { was found. The Odd's } \\
\text { ratio showed that the risk of low birth weight in pregnant women with } \\
\text { periodontitis was } 15.58 \text { times higher compared to those who did not suffer } \\
\text { from periodontitis. The periodontal disease index has an accuracy of } 88.6 \% \text { in } \\
\text { predicting the incidence of LBW. It strongly influenced the incidence of LBW } \\
\text { with a high Odd's ratio of } 28.0 \text {. Pregnant women who suffer from periodontitis } \\
\text { with a PDI > 3.25, have } 19.2 \text { times higher risk for delivering babies with LBW } \\
\text { compared to the non-periodontitis mothers. }\end{array}$ \\
\hline December 29, 2015 & Conclusions: The loss of attachment affects the possibility of delivering LBW \\
\hline Revised: & \\
\hline & Keywords: Periodontitis, periodontal disease index, low birth weight \\
\hline $\begin{array}{l}\text { Accepted: } \\
\text { March 7, } 2016\end{array}$ & IJIHS. 2016;4(1):15-9 \\
\hline
\end{tabular}

\section{Introduction}

Periodontitis is regarded as an infection in the tooth supporting tissues which leads to inflammation, loss of epithelial attachment, and alveolar bone destruction. The common clinical characteristics of chronic periodontitis are supragingival and subgingival plaque, as well as calculus accumulation, gum inflammation, paperback formation, attachment loss and alveolar bone destruction. Thus, this condition can be clinically diagnosed by examining the changes that occur in the gingival margin such as bright red color, swelling, missing stippling, and round or blunt interdental papilla. ${ }^{1}$

\footnotetext{
Correspondence:

Ira Komara, Department of Periodontology, Faculty of Dentistry, Universitas Padjadjaran

Jl. Sekeloa Selatan I, Bandung, Indonesia

e-mail: ikomara_perio@yahoo.com
}

During pregnancy, maternal hormones and cytokines have an important role in regulating the time of delivery, the opening of the cervical, uterine contractions, and labor.

Additionally, the strength of the relationship between the periodontal disease and preterm birth incidence increases frequently along with the severity of periodontitis. Huck et al. ${ }^{3}$ also suggested that women population with a high prevalence of severe periodontitis are at risk for preterm birth. Besides, pregnant women who were involved in the study did not have other major risk factors that led to premature delivery as genitorurinari infection, smokers, and alcohol drinkers.

As a periodontal infection occurs to serve as a bacterial reservoir that may exacerbate systemic diseases. A previous study suggested that the bacteria that cause inflammation in 
the gums can actually get into the bloodstream and target the fetus, potentially leading to premature and low-birth-weight babies. ${ }^{4}$

Periodontal disease in pregnancy is a source of chronic infection which has the potential to cause deleterious effects on the mother and fetus leading to premature low-birth-weight babies. $^{5}$

The results of the study on prematurity and growth retardation showed that pregnant women who suffered from periodontal disease have contributed to two kinds of risks. These are prematurity with low birth weight and low birth weight by gestational age. The study confirmed the need to consider periodontal disease as a new potential cause of prematurity and growth retardation. ${ }^{5}$

Periodontitis has long been suspected to play a role as a risk factor for several systemic diseases such as coronary heart disease (CHD), Diabetes mellitus and upper respiratory tract infection. However, based on studies in recent years, periodontitis has also been implicated as a risk factor for prematurity and low birth weight (LBW) babies. ${ }^{6}$ A study suggested that periodontal treatment in pregnant women can reduce the risk of preterm birth and low birth weight. $^{5}$

Additionally, the prevalence of periodontitis in Indonesia until now is still relatively high, by use of the Community Periodontal Index of Treatment Needs (CPITN) research. It turns out that $66 \%$ of the society requires action oral hygiene instruction and scaling due to calculus deposits and $32 \%$ of this amount has been suffering from chronic marginal periodontitis with pockets ranging from 4-5 mm. ${ }^{7,8}$

The purpose of this study is to identify the relationship between periodontitis in pregnant women through the periodontal disease index (PDI) and low birth weight babies.

\section{Methods}

This study was a case-control study. The subjects were mothers with periodontitis and non-periodontitis aged between 20-35 years who had given birth in the Department of Obstetrics and Gynecology, Dr. Hasan Sadikin General Hospital, Bandung from December to January, 2005.

The sampling method used was the rule of thumb that for every variable included was a minimum of 10 samples. Then, based on these calculations, 35 samples were obtained for each study group and control group.
The variables measured as indicators of periodontitis are the periodontal disease index by measuring the level of attachment loss from the cemento enamel junction to the base of the pocket. Meanwhile, for low birth weight babies, the variables were those who were born weighting less than 2500 grams. Checking the level of attachment loss was performed by using the Williams periodontal probe at 6 Ramfjord tooth surfaces which were: distobuccal, buccal, mesiobuccal, distolingual, lingual and mesiolingual on teeth: 16, 21, 24, 36, 41, 44.

Samples of homogeneity were conducted by the $t$ test. In order to analyze the correlation between periodontitis and LBW, a chi squared test was performed. While to predict the occurrence of LBW, a cut off point based on the receiver operating characteristic (ROC) curve was executed. To determine the effect of the variable to LBW by calculating the odds ratio and risk factors for LBW, the multiple logistic regression analysis was performed.

\section{Results}

The case-control study of the relationship of chronic marginal periodontitis disease in pregnant women with the incidence of low birth weight babies was carried out in the Department of Obstetrics and Gynecology, Dr. Hasan Sadikin General Hospital, Bandung.

The subjects of this study were mothers who has given birth to low birth weight babies and maternal control for the normal weight babies. The numbers of participants were 70 mothers based on the Consecutive Sampling (in order of coming patients) who merit the inclusion and exclusion criteria. Out of 70 mothers, there were 12 mothers gave birth to low birth weight babies $(<2.500 \mathrm{~g})$ and the remaining 58 mothers gave birth to a aby with normal baby weight (NBW) $(>2.500 \mathrm{~g}$ ). In addition, all participants had attachment of loss check which were an indicator for a periodontal disease.

While, the maternal age in both groups did not have a significant difference $(p=0.603)$ (Table 1). Thus, it was suitable to be compared. The results of the PDI between groups of mothers with maternal LBW and NBW showed significant difference. From these results, the average of the PDI in the group showed that women with LBW were higher than mothers with NBW.

Based on the results of the PDI, it can determine the incidence of chronic marginal 
Ira Komara, Soertini E. Lambri, et al.

Table 1 Comparison of the Average Maternal Age and Periodontal Disease Index

\begin{tabular}{|c|c|c|c|}
\hline \multirow{2}{*}{ Variable } & \multicolumn{2}{|c|}{ Groups } & \multirow{2}{*}{ p Value } \\
\hline & Low Birth Weight ( $n=12)$ & Normal Baby $(n=58)$ & \\
\hline Age ( year) & 0,52 & 0,603 & \\
\hline$<25$ & 5 & 21 & \\
\hline $25-29$ & 3 & 17 & \\
\hline $30-34$ & 4 & 16 & \\
\hline$>35$ & - & 4 & \\
\hline$x(s d)$ & $26.5(4,1)$ & $27.4(5,4)$ & \\
\hline Range & $19-32$ & $18-41$ & \\
\hline PDI & & & $<0,001^{*}$ \\
\hline $\mathrm{x}(\mathrm{SD})$ & $3.27(1,03)$ & $2,38(0,62)$ & \\
\hline Range & $1.775-5.47$ & $1.0-3.66$ & \\
\hline
\end{tabular}

periodontitis (Table 2). The incidence of periodontitis in maternal LBW group was 11 cases $(91.7 \%)$, while the group of mothers with NBW was $24(41.4 \%)$. Based on the test results of the chi squared test, it showed a significant relationship between periodontitis and low birth weight $(\mathrm{p}=0.002)$. The results of the Odd's ratio were 15.58. Meaning that the risk of LBW in the case of periodontitis was 15.58 times compared to mothers who did not suffer from periodontitis.

Afterwards, based on the calculation of the PDI, it obtained the cut-off point (limit value), which could be used to predict the occurrence of the LBW by calculating the ROC (receiver operating characteristic) curve.

The results of the calculation of the cut off point for PDI was $>3.25$. The results of the calculation of sensitivity, specificity and accuracy of the cut-off point are described (Table 3).

Table 2 Relationship between Periodontitis with Low Birth Weight

\begin{tabular}{lcc}
\hline \multirow{2}{*}{ Periodontitis } & \multicolumn{2}{c}{ Groups } \\
\cline { 2 - 3 } & $\begin{array}{c}\text { Low Birth } \\
\text { Weight } \\
\text { (n=12) }\end{array}$ & $\begin{array}{c}\text { Normal Baby } \\
\text { (n=58) }\end{array}$ \\
\hline+ & $11(91,7 \%)$ & $24(41,4 \%)$ \\
- & 1 & 34 \\
\hline$X^{2}=10,057 ; p=0,002$ & \\
\multicolumn{2}{c}{ OR $=15,58(95 \% \mathrm{CI}: 1,88-128,87)$} &
\end{tabular}

Apparently, PDI had an accuracy of $88.6 \%$ in predicting the incidence of low birth weight babies (Table 3). To determine the effect of various variables, measured by the cut-off point on the incidence of LBW, the results are described (Table 4). It showed that PDI strongly influenced the incidence of low birth weight babies with higher Odd's ratio of 28.0.

Furthermore, the multivariate analysis was used in this study; the variables included were the PDI and periodontitis in relation to the incidence of low birth weight by using multiple logistic regression analysis. Results were only incidences of periodontitis and PDI (Table 5). The effect of chronic marginal periodontitis in pregnant mothers for the occurrence of LBW was 10.90 times higher than in pregnant mothers without periodontitis, while to those who had PDI more than 3.25, the risk of LBW was 19.2 times more higher than normal.

\section{Discussion}

There were 70 subjects involved in this study. The subjects were selected by consecutive sampling (in order of coming patients) who met the inclusion and exclusion criteria. Out of 70 , there were 12 babies with low birth weight $(<2,500 \mathrm{~g})$, and the remaining 58 mothers gave birth to a normal baby (NBW) $(>2,500$ g). The tests carried out on both groups were the accumulation of plaque, gingival bleeding, probing depth and attachment loss, which were indicators for chronic marginal periodontitis. 
Table 3 Sensitivity, Specificity, and Accuracy of Measurement Results (cut-off value point) in Predicting Low Birth Weight Infants

\begin{tabular}{|c|c|c|c|c|c|}
\hline Cut off point & $\begin{array}{c}\text { Low Birth } \\
\text { Weight }(n=12)\end{array}$ & $\begin{array}{c}\text { Normal Baby } \\
(n=58)\end{array}$ & $\begin{array}{c}\text { Sensitivity } \\
(\%)\end{array}$ & $\begin{array}{c}\text { Spesifisity } \\
(\%)\end{array}$ & Accuracy (\%) \\
\hline \multicolumn{6}{|l|}{$\begin{array}{l}\text { Periodontal } \\
\text { disease index }\end{array}$} \\
\hline$>3.25$ & 6 & 2 & 50 & 96.6 & 88.6 \\
\hline$<3.25$ & 6 & 56 & & & \\
\hline
\end{tabular}

The results of this study viewed from a comparison of the average age of mothers who have given birth in the two groups showed that there is no significant difference $(\mathrm{p}=0.603)$. Meaning that the mothers' age group in this study consisting of mothers suffering from chronic marginal periodontitis, had the same risk of having a baby with low birth weight. Based on the results both of them could be compared.

Furthermore, the results of the PDI among mothers who give birth to LBW babies and who give birth to NBW babies shows a significant difference. The average of the PDI on maternal LBW group is higher than NBW mothers.

The results of this study shows a significant relationship between the chronic periodontitis marginalis and the low birth weight $(p=0.002)$ (Table 2). Thus, the Odd's ratio of computation magnitude is 15.58 which means that the risk of LBW in mothers with chronic marginal periodontitis is 15.58 times higher than in mothers with periodontitis who give birth to babies with normal weight. The results are also in accordance with the study of Mathew et al. ${ }^{5}$ It stated that pregnant women with high risk of periodontitis are 4 times more likely to give birth to low birth weight than women who have healthy gums. There is a slight difference between the number of maternal risk of delivering low birth weight pregnant patients with periodontitis in the United States and in Dr. Hasan Sadikin General Hospital, Bandung, Indonesia. This difference is most likely due to the level lifestyle in America is much higher compared to Indonesian society, such as in the social, economic, health, educational, environmental, and cultural aspects. ${ }^{10}$

The results of measurements of the PDI that have a value of $88.6 \%$ in predicting the incidence of LBW is in line with the opinion of Rateitschak et al. ${ }^{11}$ on the pathogenesis of periodontal disease (Table 3). Periodontitis occurs in stage 4 which histologically has been a proliferation of epithelial apical direction, ulcerated junctional epithelium and increased loss of attachment in the connective tissue.

The results show that PDI (28.0) is strongly influenced by the occurrence of LBW with $95 \%$ confidence interval (Table 4). This is in accordance with the opinion of Mathew et al. ${ }^{5}$ that periodontal disease is a significant risk factor for the occurrence of LBW.

The marginal effect of chronic periodontitis in pregnant mothers in the occurrence of LBW was 10.90 times when compared to pregnant

Table 4 Relationship between the Incidences of Periodontal Disease Index and Low Birth Weight Babies

\begin{tabular}{lccccc}
\hline \multicolumn{1}{c}{ Variable } & $\begin{array}{c}\text { Low Birth } \\
\text { Weight }\end{array}$ & $\begin{array}{c}\text { Normal } \\
\text { Baby }\end{array}$ & $\mathbf{X}$ & p Value & OR (95\% CI) \\
\hline $\begin{array}{l}\text { Periodontal Disease } \\
\text { Index }\end{array}$ & & & 21.286 & $<0.001$ & $28.0(3.74-267.19)$ \\
$>3.25$ & 6 & 2 & & & \\
$\leq 3.25$ & 6 & 56 & & & \\
\hline
\end{tabular}

$\mathrm{X}=$ Chi square test

OR $(95 \% / \mathrm{CI})=$ Odd's ratio value and $95 \%$ confidence interval 
Table 5 Results of the Relationship between Risk Factors with the Incidence of Low Birth Weight which was Statistically Significant (Late Model)

\begin{tabular}{lcccc}
\hline \multicolumn{1}{r}{ Variable } & Coef $\boldsymbol{\beta}$ & SE $(\boldsymbol{\beta})$ & p Value & Odd's Ratio Value $(\mathbf{9 5 \%} \mathbf{C I})$ \\
\hline Periodontitis & 2.3887 & 1.1389 & 0.036 & $10.90(1.17-101.59)$ \\
PDI & 2.9458 & 0.9994 & 0.003 & $19.02(2.69-134.65)$ \\
Constanta & -3.8459 & 1.0773 & & \\
\hline B = Regression coeficient & & &
\end{tabular}

$\mathrm{SE}=$ Standard error

$\mathrm{OR}=$ Odd's ratio

mothers without periodontitis (Table 5). While, for PDI $(>3.25)$ the risk of the occurrence of LBW is 19.2 times compared to normal.

In conclusion, periodontitis and PDI with lost of attachment, either jointly or individually influence the incidence of LBW. These results are in line with the results presented by Mathew et al. ${ }^{5}$ that pregnant mothers have the possibility of periodontitis 4 times more likely to give birth to low birth weight babies. The pregnant women who participated in the study do not have other major risk factors that can lead to premature delivery as genitorurinary infection, smokers, and alcohol drinkers. In this study, those single factors are not found.

\section{References}

1. Wiebe CB, Petricca G, Häkkinen L, Jiang G, Wu C, Larjava HS. Kindler syndrome and periodontal disease: review of the literature and a 12-year follow-up case. J Periodontol. 2008;79(5): 961-6.

2. Bansal M, Khatri M, Kumar A, Bhatia G. Relationship between maternal periodontal status and preterm low birth weight. Rev Obstet Gynecol. 2013;6(3-4):135-40

3. Huck O,Tenenbaum H, DavideauJL. Relationship between periodontal disease and preterm birth: recent epidemiological ang biological data. J Pregnancy. 2011 [cited 2015 Aug 3]:[about 9 p.]. Available from: http://www. hindawi.com/journals/jp/2011/164654/.

4. Saini R, Saini S, Saini SR. Periodontitis: a risk for delivery of premature labor and low-birthweight infants. J Nat Sci Biol Med. 2010;1(1): 40-2.

5. Mathew RJ, Bose A, Prasad JH, Muliyil JP, Singh D. Maternal periodontal disease as a significant risk factor for low birth weight in pregnant women attending a secondary care hospital

in South India: a case-control study. Indian J Dental Res. 2014;25(6):742-7.

6. Ghali RF. The potential link between periodontitis and systemic diseases- an overview. JAMR. 2011;1(1):24-35.

7. Mujur M, Sukarya WS. Kumpulan Makalah KOGI X. Padang. 1996. p. 234-5.

8. Archana V, Ambili R, Nisha KJ, Seba A, Preeja C. Acute-phase reactants in periodontal disease: current concepts and future implications. J Investig Clin Dent. 2015;6(2):108-17.

9. Lagrew DC Jr, Jenkins TR. The future of obstetrics/gynecology in 2020: a clearer vision: finding true north and the forces of change. Am J Obstet Gynecol. 2014;211(6):617-22.

10. Iams DJ, Creasy RK. Maternal-Fetal Medicine Principles and Practise. Philadelphia: WB Sauders; 2004. p. 623-636.

11. Rateitschak KH, Rateitschak EM, Wolf HF, Hassell TM. Color Atlas of Periodontology 10ed. Georg Thieme Verlag Stuttgart, New York; 2005. p. 67-71. 